\title{
EFFECTS OF AEROBIC EXERCISE TRAINING ON CARDIOVASCULAR AND MUSCULOSKELETAL FITNESS IN POSTMENOPAUSAL WOMEN
}

\section{Dr Priyanka Gulati (PT)}

\section{Dr. Divya Gupta} (PT)

\section{Dr Sushmita} Kushwaha* Dr Siddhartha Sen (PT)

\author{
Delhi Pharmaceutical Sciences \& Research University, Pushp Vihar, \\ M.B.Road, New Delhi.
}

Sports Physiotherapist, PGIMS, Pandit Bhagwat Dayal Sharma University of health Sciences, Rohtak, Haryana.

Assistant Professor, Sports Medicine, PGIMS, Pandit Bhagwat Dayal Sharma University of health Sciences, Rohtak, Haryana. ${ }^{*}$ Corresponding Author

Associate Professor, Delhi Pharmaceutical Sciences \& Research University, Pushp Vihar, M.B.Road, New Delhi.

ABSTRACT Background: Postmenopausal women faces a number of changes in their body which may lead to loss of health related fitness among them.

Aim: To find out effects of Aerobic exercise training in postmenopausal women as a means of improving cardiovascular and musculoskeletal fitness.

Methodology: 30 postmenopausal women within age group of 45-55years were assigned systematically into two groups as Group-A \& Group-B (15 each). Group A were provided aerobic exercise training program 3 times a week while Group B performed free body exercises for 4 weeks. The VO2 max, flexibility and core strength were measured as an outcome measures on starting day and at the end of fourth week.

Results: Statistically significant differences were found between groups for changes in the VO2 $\max (\mathrm{p}=0.001)$ Flexibility $(p=0.008)$ and Core strength $(p=0.003)$. VO2 $m a x$, flexibility and core strength data were also significant within both the groups $(\mathrm{p}<0.05)$.

Conclusion: 4 weeks of aerobic exercise training improves cardiovascular and musculoskeletal fitness in postmenopausal women.

\section{KEYWORDS : Postmenopausal women, Aerobic Exercises, Cardiovascular fitness.}

\section{INTRODUCTION}

Menopause is defined as a natural, age-related decrease and finally, loss of ovarian estrogen production and secretion along with other related hormonal changes, affects women in many unwanted ways, especially for those women who are inactive. In addition to most common problem as weight gain, menopause may also induce a phase of rapid decrease in bone mineral density, aerobic fitness, muscle strength.(1) As with menopause due to age related changes, substantial loss in tendon flexibility may occur and also leads to functional inability in doing everyday activities. (2)

Physical activity might help women make the menopausal transition with much less dramatic changes and help them to preserve good functional ability. (3) Studies have reported that involvement in physical exercise is very important in creating a healthy lifestyle and health-related fitness components such as cardio-respiratory fitness, muscular strength and endurance, body composition, flexibility as well as increases bone mineral density.(4)

With the above understanding, it is clear that the aerobic training create the foundation for a cardiovascular fitness in postmenopausal women. But, how aerobic training contribute to the musculoskeletal fitness (core strength and flexibility) in postmenopausal women is uncertain and underlies the utility of present research work. Therefore, it was hypothesized in this study that there would be statistically significant effects of aerobic exercise training on cardiovascular (Vo2 max) and musculoskeletal fitness(core strength and flexibility) in postmenopausal women.

\section{METHODOLOGY}

A total of 30 postmenopausal women between $45-55$ years of age with body mass index of 18.5 to 30 were included in the study. Subjects having any Chronic disease like hypertension, diabetes mellitus ,chronic bronchitis or suffering with active myocardial disease or knee osteoarthritis or the subjects on hormonal replacement therapy and/or on long term use of any medication were excluded from the study. All the subjects gave their written informed consent.

\section{Procedure}

All the subjects were assigned systematically into two groups as Group-A \& Group-B. Group A were provided aerobic exercise training program 3 times a week for 4 weeks while Group B performed free body exercises in that 4 weeks period.

\section{Measurement of flexibility:}

Flexibility was assessed using the sit and reach test. Participant sat on the floor with their feet approximately hipwide against the testing sit and reach box. They kept their knees extended and placed the right hand over the left, and slowly reached forward as far as they could reach. A standard meter scale was placed on the sit-and-reach box for each test. (Fig 1)

\section{Measurement Of The $\mathrm{Vo}_{2}$ Max:}

$\mathrm{VO}_{2}$ max was measured by Modified Queens College Step Test. A 17 inch bench (stepper) and a stopwatch were taken and the patients were asked to step up and step down on the stepper for one minute. After completion of one minute step test, heart rate of the patients was measured manually. Then $\mathrm{VO}_{2}$ max was calculated by a formula described by Modified Queens College Step Test. (Fig 2)

$\mathrm{VO}_{2} \max (\mathrm{ml} / \mathrm{kg} / \mathrm{min})=65.81-(0.1847 \times$ step test pulse rate beats/minute)

\section{Measurement Of Core Strength:}

The subject assumed the forearm plank position with elbows in contact with the ground, such that the humerus formed a 
perpendicular line to the horizontal plane, directly beneath the shoulders. The forearms were in neutral position and hands were directly in front of the elbows. The participants were instructed to hold this position as long as possible. The test was terminated when the participant fatigued or voluntarily stopped the test or the participant failed to maintain the proper position. (Fig 3)

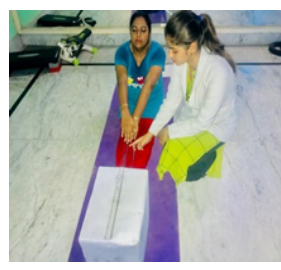

Fig 1: Sit And Reach Test

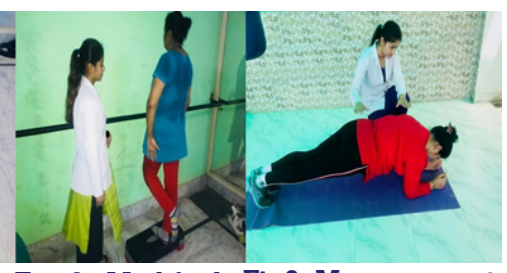

Fig 2: Modified Fig3: Measurement Step Test Of Core Strength
Experimental Protocol (Application of Aerobic Exercise Training Program)

Aerobic training was performed with Frequency of 3 days per week; intensity of training was $65 \%$ of Maximum Heart Rate. A Total of 45 minutes of activity was performed by the subjects that included warm up of 10 minutes, main program of 30 minutes and cool down exercises for 5 minutes.

Warm up exercises included knees-up in standing position, Back touch in standing position and Walking slowly for at least 5 minutes.

Main Aerobic Program included stationary cycling for five minutes at a normal pace, running for about five minutes, Aerobic dancing for fifteen minutes continuously and stair climbing.

Cool down Exercises included stretching exercise for Pectoralis major muscle, neck muscles, Quadriceps, Calf, Hamstring muscles and total body repetitive motions.

\section{Statistical Analysis}

A Pre-Test Post-Test Control Group Design was selected for testing the hypothesis. The outcome measures were the changes in $\mathrm{VO}_{2} \mathrm{Max}$, flexibility, and core strength. The data was analyzed using SPSS 11.5. Independent sample t-test was performed to see any differences between the groups and within the groups. The significance level was set at $p<0.05$.

\section{RESULTS}

Demographic profile of the subjects are shown in Table 1.

Table 1: Demographic Data

\begin{tabular}{|l|c|c|c|c|}
\hline & $\begin{array}{c}\text { Age } \\
\text { (in years) } \\
\text { (mean } \pm \text { sd) }\end{array}$ & $\begin{array}{c}\text { Height } \\
\text { (in meters) } \\
\text { (mean } \pm \text { sd) }\end{array}$ & $\begin{array}{c}\text { Weight } \\
\text { (in Kgs) } \\
\text { (mean } \pm \text { sd) }\end{array}$ & $\begin{array}{c}\text { BMI } \\
\text { (in Kg/m2) } \\
\text { (mean } \pm \text { sd) }\end{array}$ \\
\hline Group A & $49.53 \pm 2.92$ & $1.62 \pm 0.10$ & $68.40 \pm 7.22$ & $25.86 \pm 2.66$ \\
\hline Group B & $50.40 \pm 3.56$ & $1.57 \pm 0.03$ & $61.52 \pm 5.71$ & $24.78 \pm 2.01$ \\
\hline
\end{tabular}

Paired sample t test was used to find out significant difference within the Group A. The results showed significant differences of $\mathrm{VO}_{2} \max (\mathrm{p}=0.0001)$, Flexibility $(\mathrm{p}=0.0001)$, Core strength $(p=0.0001)$ between pre and post outcome. Paired sample $t$ test was also used to find out significant difference within the Group B. The results showed significant differences of $\mathrm{VO}_{2}$ $\max (p=0.0001)$,Flexibility $(p=0.0001)$, Core strength $(p=0.009)$ between pre and post outcome.

Independent Sample t test between the groups was used to find out difference between the groups. The results showed non significant differences of $\mathrm{VO}_{2} \max (p=0.318)$, Flexibility $(p=0.258)$,Core strength $(p=0.237)$ for pre outcome and showed significant difference of $\mathrm{Vo}_{2} \max (p=0.001)$, Flexibility $(p=0.008)$, Core strength $(p=0.003)$ for post outcome.
Table 2: Independent Sample T Test Between The Groups

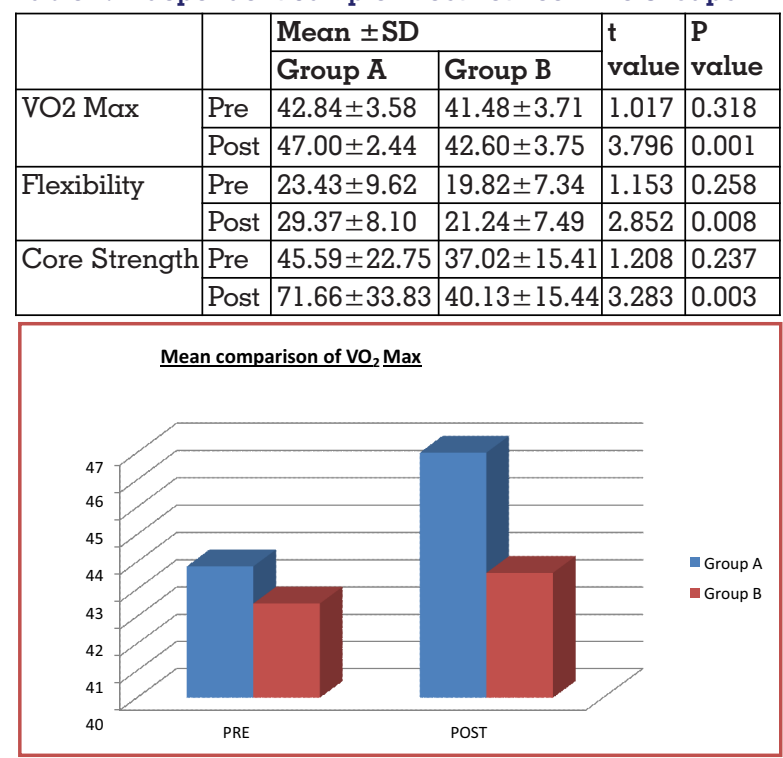

Graph 1: Mean Comparison Of Sample T Test Between The Groups For $\mathrm{Vo}_{2} \mathrm{Max}$

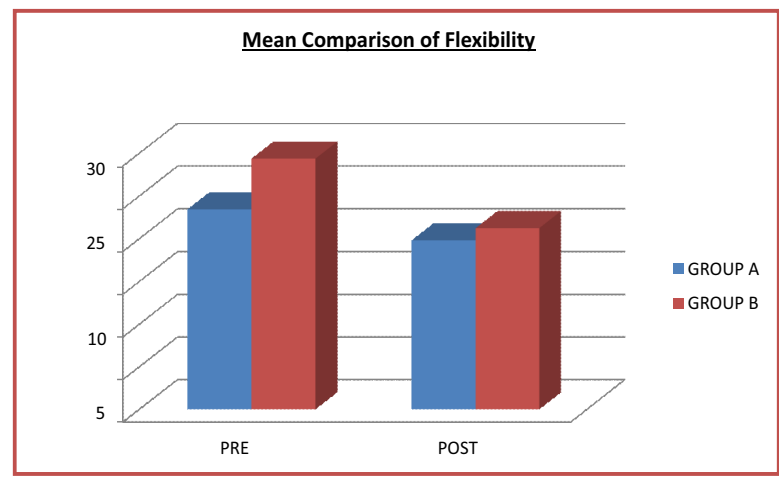

Meangraph 2: Mean Comparison Of Sample T Test Between The Groups For Flexibility

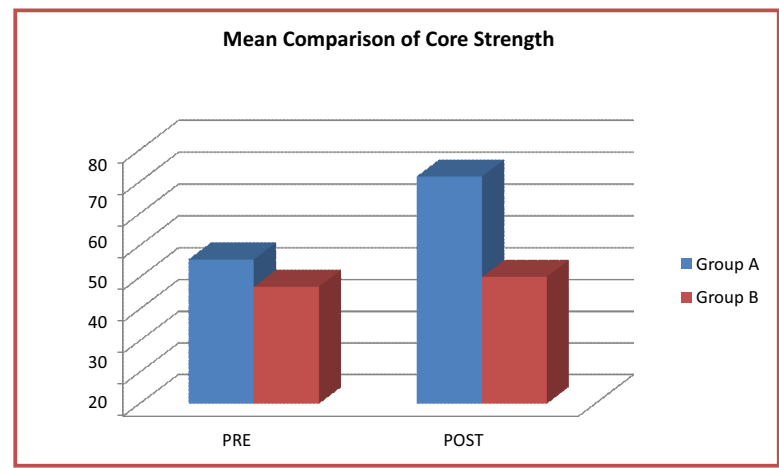

Graph 3: Mean Comparison Of Sample T Test Between The Groups For Core Strength

\section{DISCUSSION}

The present study supports the hypothesis that aerobic exercise training is far better than free body exercises for improving musculoskeletal and cardiovascular fitness in postmenopausal women. When compared with the values for $\mathrm{VO}_{2} \mathrm{Max}$ between the two groups, aerobic exercise trained experimental group showed greater improvement than control group. Literature suggested that the increase in capillary bed volume with aerobic training contributed to the increase in $\mathrm{VO}_{2}$ max as it prevents the decrease in capillary mean transit time and $\mathrm{O}_{2}$ extraction.(5) Another explanation for rise in $\mathrm{VO}_{2}$ max is due to rise in cardiac output at the time of maximal exercise.(6) 
The possible explanation for improvement in core strength is suggested in literature by increase in the muscle fibre type distribution (the percentage of type IIa) and cross-sectional area of the type I and type IIa fibres after aerobic training in their study.(5) Studies have also observed larger slow twitch fibres (type I) and skeletal muscle adaptations post aerobic exercise training.(7)

Aerobic exercise training used in present study appeared to be more effective in improving the flexibility of postmenopausal women as compared to free body exercises. Literature suggested that acute prolonged running program and aerobics induced an increase in type I collagen synthesis, which is indicated by changes in plasma concentration of carboxyterminal propeptide of type I procollagen (PICP) i.e marker of collagen formation.(8) This can be explained easily as running is one of the basic component of aerobic exercise program used in present study but not a part of control group exercises.

Few limitations of present study were small sample size and less exercise duration of 4 weeks. The effects of the interval aerobic training and continuous aerobic training was not compared in the present study and can be analyzed in the future. The relation of the exercise with premenopausal women was not analyzed in the present study and can be analyzed in the future. Further studies can also be conducted to study the combined effects of aerobic, strength or circuit training in post menopausal women.

\section{CONCLUSION}

The present study concluded that 4-week aerobic exercise training improved cardiovascular and musculoskeletal fitness in Postmenopausal women.

\section{REFERENCES}

1. Sowers, M.R., La Pietra M.T.(1995).Menopause: its epidemiology and potential association with chronic diseases.Epidemiologic Reviews ,17(2), 287-302.

2. Fatouros K. Taxildaris S. P. Tokmakidis V. Kalapotharakos N. Aggelousis S. Athanasopoulos I. Zeeris I. Katrabasas.(2002)The Effects of Strength Training, Cardiovascular Training and Their Combination on Flexibility of Inactive Older Adults. Int J Sports Med. 23,112-119

3. Wojtek, J. David N. Proctor, Maria A. Fiatarone Singh, Christopher T. Minson, Claudio R. Nigg, George J. Salem, \& James S. Skinner.(1998).Exercise and physical activity for older adults.[American College of Sports Medicine Position Stand]. Med Sci Sports Exerc.30,992-1008

4. Wolfgang Kemmler, Dirk Lauber, Ju"rgen Weineck, PhD, Johannes Hensen, Willi Kalender\& Klaus Engelke.(2004)Benefits of 2 years intense exercise on bone density, physical fitness and blood lipids in early postmenopausal osteopenic women. Results of the

Erlangen Fitness Osteoporosis Prevention Study (EFOPS). Arch Intern Med.,164,1084-1091.

5. Coggan, Andrew R., Robert J. Spina,Douglass.King, Mark A. Rogers,Marybeth Brown,Patti M.Nemeth \& John O.Holloszy.(1992) Skeletal muscle adaptations to endurance training in 60- to 70-yr-old men and women. J. Appl. Physiol,72(5), 1780-1786.

6. Andrew M. Jones and Helen Carter.(2000). The Effect of Endurance Training on Parameters of Aerobic Fitness. Sports Medicine, 29 (6), 373-386.

7. P.D. Gollivick, R. B. Armstrong, B. Saltin C. W. Saubert IV, W. L. Sembrowich, R.E. Shepherd.(1973).Effect of training on enzyme activity and fiber composition of human skeletal muscle. J. Appl. Physiol. 34(1): 107-111.

8. H. Langberg, D. Skovgaard, S. Asp, M. Kjær.(2000).Time Pattern of ExerciseInduced Changes in Type I Collagen Turnover after Prolonged Endurance Exercise in Humans. Calcif Tissue Int. 67,41-44. 